\title{
Special issue on IEEE LASCAS2010
}

\author{
Eric Kerhervé • Ricardo Reis • Antonio Garcia Rozo
}

Published online: 8 January 2012

(C) Springer Science+Business Media, LLC 2012

This special issue of the Springer Analog Integrated Circuits and Signal Processing (ALOG) is devoted to selected topics from the First IEEE Latin American Symposium on Circuits and Systems (LASCAS2010) that was held in Iguaçu Falls, Brazil, 24th-26th February 2010. LASCAS is intended to be the IEEE Circuits and Systems Society flagship and international conference in Latin America. The selected papers reflect continuing trends toward higher levels of analog and digital circuit techniques covering a wide variety of subjects within the Analog and RF Integrated Circuits, Signal Processing, Digital Integrated Circuits and EDA fields, ranging from basic analog building blocks to system applications on several related domains.

The major areas of Electronics, Circuits and Systems covered by LASCAS2010, drew 125 submissions from 30 countries spanning the globe (52\% of submitted papers were from out of Latin America) and 53 contributions were selected by more than 75 reviewers for oral presentations and 21 for poster presentation. Among the published contributions in the LASCAS2010 proceedings, a pre-selection of 11 papers has been completed and corresponding Authors were invited for contributions to this Special issue. After receiving the full manuscripts and the assessment of

\section{E. Kerhervé}

IMS Laboratory, Université Bordeaux 1, Bordeaux, France

e-mail: eric.kerherve@ims-bordeaux.fr

\section{R. Reis $(\bowtie)$}

Instituto de Informática, PGMicro/PPGC, Universidade Federal do Rio Grande do Sul (UFRGS), Porto Alegre, Brazil

e-mail: reis@inf.ufrgs.br

\section{A. G. Rozo}

Microelectronics Center, Uniandes-Los Andes University, Bogota, Colombia

e-mail: angarcia@uniandes.edu.co reviewers, eight of them have been accepted for publication in this Special issue.

The presented contributions in this Special issue deal with arithmetic circuits, IC architectures, power amplifiers, switching, FFT and variability and defects monitoring circuits dedicated for numerous building blocks of several applications. These contributions includes: (1) FPGA realization of high performance large size computational functions: multipliers and applications; (2) Design challenges of a fully integrated $65 \mathrm{~nm}$ CMOS half cascode SFDS PA; (3) An efficient parallel architecture for raytracing; (4) A linear $60 \mathrm{GHz} 65 \mathrm{~nm}$-CMOS power amplifier realization and characterization for OFDM signal; (5) Automatic adjustment of a medical imaging data acquisition system to unknown delays in the input communication channels; (6) Analysis of the conditions for the worst case switching activity in integrated circuits; (7) FPGA implementation and testing of a 128 FFT for a MB-OFDM receiver; (8) Delay sensing for long-term variations and defects monitoring in safety-critical applications.

Selecting only 8 papers out of 125 contributions of the conference presentations is a difficult and critical task. We are aware that we probably missed many excellent contributions, but we do know that we did our best to put together a special issue as complete as possible.

The Technical Program of LASCAS2010 is the result of a truly international cooperation of experts. We feel very much indebted to Technical Program Committee for their invaluable help to start LASCAS at the high standard that our scientific community has grown accustomed to expect from an CASS symposium. We wish to thank our coresearchers from all around the world, for choosing to submit their contributions to LASCAS for review. Due to their many and important contributions, we managed to create a Technical Program of high scientific quality. 
In fact, it has been gratifying to learn more about the advances first described at LASCAS2010. We would like to thank the numerous volunteers that helped to review the submitted papers. We wish to thank IEEE CASS and the LASCAS Steering Committee to let organizing this new prestigious IEEE conference in Iguaçu Falls and to Professor Mohamed Ismail, Editor-in-chief of ALOG a for giving us the opportunity to lead this special issue. We also wish to express our deepest gratitude for the efforts of the Springer personnel. This special issue is only possible with their expert help.

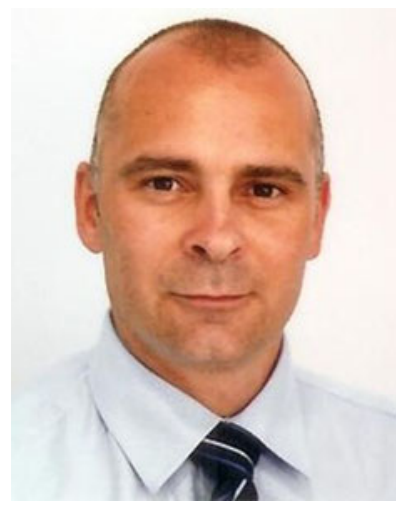

Eric Kerhervé received the $\mathrm{Ph} . \mathrm{D}$. degree in Electrical Engineering from University of Bordeaux, France in 1994. He joined IPB ENSEIRB-MATMECA (Polytechnic Institute of Bordeaux) and the IMS Laboratory in 1996, where he is currently Professor in Microelectronics and Microwave applications. His main area of research focuses on the design of RF, microwave and millimeter-wave circuits (power amplifiers and filters). He is or was involved in European projects, as MEDEA + UPPERMOST, FP6 MOBILIS, MEDEA + QSTREAM, CATRENE PANAMA, ENIAC MIRANDELA to develop silicon power amplifiers and BAW duplexer. He has authored or co-authored more than 190 technical papers in this field, and was awarded 17 patents. He has organized 6 RFIC workshops on advanced silicon technologies for radiofrequency and millimeter-wave applications. He is involved in the technical program committees of various international conferences (ICECS, IMOC, NEWCAS, EuMIC, SBCCI) and he was the chair of IEEE ICECS'2006 and IEEE NEWCAS'2011 conferences. He is IEEE senior member. Since 2010, he is associate editor of IEEE TCAS-II.

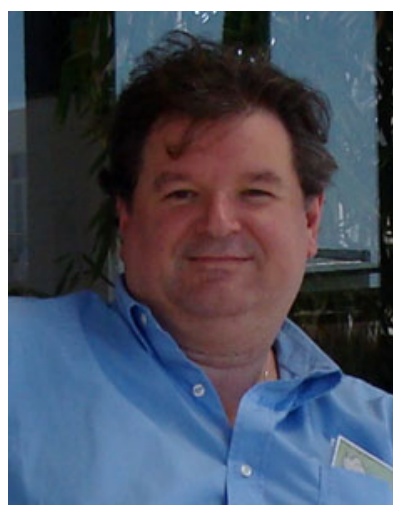

Ricardo Reis received the Ph.D. degree in Computer Science, option Microelectronics from Institut National Polytechnique de Grenoble (INPG), France in 1983. Ricardo Reis received the Electrical Engineering from the Federal University of Rio Grande do Sul (UFRGS), Porto Alegre, Brazil, in 1978. Full Professor at Instituto de Informática of UFRGS. Currently Head of the Microelectronics Graduate Program at UFRGS. Member of the Microelectronics Committee of the National Council for Scientific and
Technological Development (CNPq). His primary research interests include Physical Design Automation and Methodologies, CAD tools, Circuits Tolerant to Radiation, VLSI Design Methodologies and Microelectronics Education. He has published more than 400 hundred papers in journals and conferences proceedings (like IEEE Design \& Test, IEEE TCAS-1, IEEE TVLSI, IEEE TIE, ACM TODAES, IEEE JSSC, ISCAS, SBCCI, PATMOS, VLSI-SoC, DAC, DATE, ICCD, CICC, ASP-DAC, IEEE ISVLSI, LATW). He is also author, co-author or editor of more than 20 books. He got also some papers awards and he received an award as research of the year from the Fapergs (Science Foundation of Rio Grande do Sul) in 2002. Silver Core award from IFIP. Ricardo Reis is research level 1A of the CNPq (Brazilian National Science Foundation) and head of several research projects supported by Government Agencies and Industry. Past head of the Graduate Program on Computer Science at UFRGS (two terms), where he is a thesis advisor. He served as a General Chair or Program Chair of several conferences like the IFIP/IEEE VLSI-SoC, IEEE ISVLSI, IEEE LASCAS, Symposium on Integrated Circuits and Systems Design (SBCCI) and Congress of the Brazilian Microelectronics Society (SBMicro). Reis is founder/co-founder of several conferences like SBCCI, LASCAS, EMicro, SERESSA, CASS R9 Summer Schools. He is Past President of the Brazilian Computer Society and Past Vice-President of the Brazilian Microelectronics Society. He was vice-president of IEEE Circuits and Systems Society (2008-2011). Ricardo is member of the Editorial Board of IEEE Design \& Test and past chair of the Steering Committee of the IFIP/ IEEE VLSI-SoC series of conferences. Ricardo Reis is a senior member of IEEE.

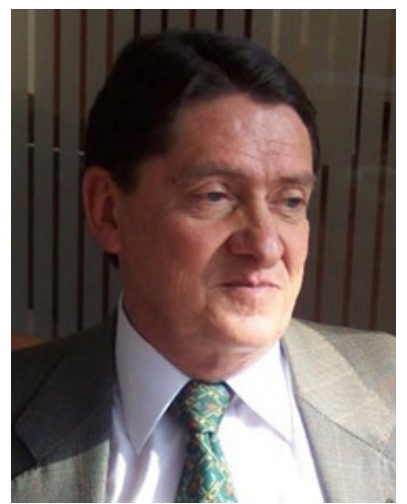

Antonio Garcia-Rozo received the Electronic Engineer degree in 1972 from the Javeriana University of Bogota, and the Diploma de Alta Gerencia in 1979 from los Andes University of Bogota. He is actually Full Professor of Los Andes University and Director of the Microelectronics Center, CMUA, of the same University. He has been Dean and Associate Dean of the Engineering School (1982-1989) of Los Andes University, and Head of Electrical an Electronic Department (1979-1982). He is member of the executive comity of the IBERCHIP project and he is member of the Advisory Board of the IberoAmerican Science and Technology Program, CYTED, in the TIC Research Area. He has also authored/co-authored more than 70-refereed papers in conference proceedings and in technical journals. He has published three books and two chapters in research books. His research interest areas are: High Level System Design, IC design, and Technology and Society Studies. He is Senior Member of IEEE and has been President of the IEEE Colombian Sectional, Chair of the Colombian CASS Chapter and President of ACIEM (Colombian Engineering Association). 